\title{
Designing to Promote a New Social Affordance for Energy Consumption
}

\author{
Lara S.G. Piccolo, Heiko Hornung, Cecília Baranauskas, and Roberto Pereira \\ Institute of Computing, The State University of Campinas - UNICAMP \\ larapicc@gmail.com, heix@gmx.com, \\ cecilia@ic.unicamp.br, roberto.ihc@gmail.com
}

\begin{abstract}
The relation between energy consumption and its environmental impact is weak or even almost inexistent in the Brazilian scenario due to sociocultural reasons. This work takes advantage of an experimental smart grid deployment scenario to propose the concept of Social Eco-feedback Technology. It aims at establishing this relation by promoting a new social affordance (behavior pattern), favoring a new way of perceiving energy. The concept of affordance and artifacts of the Organizational Semiotics are extended to encompass both the analysis of actual and intended behavior through a new technology design.
\end{abstract}

Keywords: Eco-feedback technology, Energy consumption, Affordances, Motivation, Human-Computer Interaction, Organizational Semiotics.

\section{Introduction}

The smart grid wave [36] is a manifestation of the need to rethink the way energy has been generated, distributed, and used around the world, especially considering that the natural resources of the planet have already been over-consumed, although not equally distributed among the whole population [37]. Energy companies throughout the world have specific interests in deploying smart grid technologies [4] capable of lowering costs of energy distribution, reducing demand during peak time, etc. Mainly in developed countries, providing more detailed information about how energy has been consumed, a possible feature that might be related to the smart grid technology, has been considered a crucial step for consumption reduction as a response to the pressure for restraining the climate change [4].

In the Human-Computer Interaction (HCI) domain, energy consumption is emerging as an important topic of interest [23] and many different approaches have been adopted to design consumption displays intending to promote a more sustainable individual behavior. According to the review of energy related-work by Pierce and Paulos [24], other studies that focus on the design and evaluation of energy consumption feedback are situated in domestic upper-middle class population of "developed" contexts. 
Some particularities of Brazil have framed energy-related research in the country in the last years, in such way that the importance of the connection between consumption and the natural environment by individuals has been underestimated.

Comparing it to other countries, especially to the United States and Europe, the energy is mostly generated by hydro plants, which are less polluting than thermoelectric power, commonly used worldwide [7]; the energy consumption per capita in Brazil is below the world average - in 2009 the Brazilian average reached $2.206 \mathrm{kWh}$, while the world average was $2.806 \mathrm{kWh}$; in the United States it was $12.900 \mathrm{kWh}$ and in Europe $6.063 \mathrm{kWh}[2]$.

Nevertheless, Brazil was set in the last position in a 17 countries ranking of a survey that inquired people about the correlation between environmental impact and energy consumption. Asked about factors with a negative impact on the environment, only $27 \%$ of Brazilians respondents mentioned individual energy consumption [1]. Results from a survey situated in this research scenario reinforce this panorama. Participants were asked "how do you believe that saving energy might contribute to the environment?" In low-income areas, $85 \%$ of respondents said to not know the answer, while only $7 \%$ correlated energy usage with new dams or power plant building. These results are related to socioeconomic level of the population, but the "I do not know" answer was in general predominant [22]. The survey, part of two smart grid programs also pointed out the consensual interest $(95 \%)$ in receiving more information about conscious consumption, as well as the lack of awareness of people's own consumption: in one of the areas, $90 \%$ declared not to know the average of their consumption in $\mathrm{kWh}$.

While these numbers provide an overview about how people perceive individual energy consumption and connect it to environmental impacts, 71 new hydro plants have been planned and built from 2008 to 2017 according to the official national plan of energy generation [3], in addition to the 140 already in operation, in order to supply the increasing demand resulting from the economic development and the forecasted population growth.

Coping with this scenario, this study aims at promoting a new social affordance [30][17] regarding energy consumption, which means favoring a new way of perceiving and relating to energy and the natural environment, leading to different patterns of behavior. In line with [4] and [24], this study intends to take advantage of an experimental deployment of smart grid in Brazil to establish this new relation by means of a technology introduction that has been designed with this purpose. To situate this investigation in the Brazilian context considering socio and cultural aspects in the design, the Organizational Semiotics (OS) [30][17] approach has been the theoretical basis.

In the next session, an overview eco-feedback technology is presented highlighting the need to consider the social context of its usage. Then, we propose the Social Energy Eco-Feedback Technology concept, by mapping the reality into an ontology chart. We also propose a new approach to use this artifact for representing intended behavior with the new technology design. Further session describes norms that guide the technical device development, followed by a discussion regarding OS methods and results. The last session concludes and points out future works. 


\section{The Role of Eco-feedback Technology}

In the energy consumption domain, feedback has been defined by Spagnolli [29] as "information about the consequences of household actions that involve electricity consumption", and awareness as a condition for conservation, since it represents the "knowledge users acquire about how and why to reduce waste by operating devices more efficiently, including hints that show a larger environmental impact".

Ambient displays, mobile devices, and online visualizations are possible types of Eco-feedback Technology (EFT) designed to incite the transformation of individual's behavior regarding the environment [9]. The presence of an EFT was found to lead to a consumption reduction between 5 and $20 \%$ [4][23].

Froehlich et al. [9][8] evaluated design aspects and motivational techniques for EFT such as goal-setting, comparison, incentive, etc., pointing out some open issues in the HCI area, especially when considering the social domain of the EFT usage, such as the effectiveness of competition as a motivational strategy. In [24], the authors identified works that have raised some criticism regarding the approach that deals only with individual's behaviors, disregarding the social dynamics. Dourish [6] argues that this dominant approach into environmental topics in HCI is self-limiting. Besides addressing cultural and political aspects in the design, he suggests to "connect people through their actions and their consequences", persuading people by the empowerment of collective actions, instead of individually connecting actions to their consequences.

Other studies are also based on social strategies: [15] evaluated the effectiveness of competition, which yielded controversial results regarding this strategy; [5] proposed motivating social environments as one of the mechanisms to involve consumers with the feedback technology. This strategy relies on Social Norms and social proofs, which consider that people act in a certain way to be in line with action of others in similar context [12].

Hall [13] argues that a technical device is the best way to trigger changes in peoples' behavior. Rokeach [26], and Sanders and Atwood [28] present different experiments where computer and mass media are used to let people become aware of their values. They assert that when individuals become aware of the contradictions between their conceptions of self and their values, attitudes, or behavior, they will reorganize their values and attitudes, and thus, their behavior, in order to make them more consistent with their conceptions of self.

In the next session, a social eco-feedback technology is presented, starting from the concept of affordance, which supports the proposal of a technical solution.

\subsection{Social Affordances and Eco-feedback Technology}

Affordance is a concept associated to how people relate to the environment and to the things that are part of it. Gibson [11] defined affordance in the ecological context as a result of the relationship between physical properties of the environment and the experience of the perceiving actor, which is subjective. Norman applied this concept to design [20] proposing later [18] a distinction between real affordances — related to 
the physical properties of the world - and perceived affordances, which instead of that are subjective representations in the mind. Those properties determine how the thing could possibly be used. Taking advantage of it, no labels or instructions would be needed. More recently [19], Norman reviewed the concept centering it in the social domain. Signifier is the term Norman proposes to replace affordance, meaning what people need, and what design must provide. Social signifier is the most important class of signifier because most actions people do are social. For him, social signifiers are broader and richer than affordaces. They include culture and experiences, similarly to Stamper's social affordance idea [17].

Stamper [10] extends Gibson's concept of affordances of the ecological environment to the social environment, arguing that people as agents acting in the social environment are dependent on the knowledge that has been built up and handed down from generation to generation in a society, subsidizing the idea of Social affordances as repertories of behavior tuned to the social environment.

Darby [4] applied Gibson's concept of affordance to understand how householders have perceived and used different types of consumption feedback considering the energy bills and meters, the in-home displays, and on-line visualizations. According to Darby, introducing affordances in the study of the new technology centered the smart metering technology development on the users and in their relation to energy and the new devices.

The concept of social affordance and its nuances in terms of how people relate to the environment and socially interact with it influences the proposal of a technical artifact that aims at changing the way people perceive and relate energy and the natural environment to their actions.

\section{A Social Energy Eco-feedback Technology}

Differently from most ETF proposals, which are contextualized in the domestic domain [24], this study proposes an EFT that aims at tackling energy consumption collectively, within a social group. The Social Energy Eco-feedback Technology (SEET), or SEETree, due to the metaphor of a tree applied as a signal to connect energy and the natural environment, consists on a public display and a physical installation located in gathering areas to configure and represent results of energysaving collective actions. The way the tree is lightened represents achievements of a collective saving action. The SEETree design concept is grounded in the Organizational Semiotics approach as follows.

Organizational Semiotics (OS) is a discipline that studies information and its functions in organized domains, such as a company, a digital system, or the introduction of a new technology in society, as is the focus of this study. SO provides methods and techniques for understanding and modeling information systems, considering social and human activities as part of this system [17][33].

A set of OS methods named MEASUR - Methods for Eliciting, Analyzing and Specifying User Requirements [32][34] - supports requirements analysis by considering that an organization is a system of norms that the members share through 
signs (information). A norm then is a field of force that influences the members of the community with respect to how they behave or think [35] and can be understood as 'pattern' or 'standard', governing meanings, intentions, knowledge, responsibilities and influence exerted.

In order to propose an information system that intends to promote individual and collective awareness of electricity usage, this study relies on two methods of MEASUR: (i) Semantic Analysis Method - SAM [16]: proposes semantic models of patterns of behaviors (shared meanings) based on agents and affordances, to map ontological dependencies among them; (ii) Norm Analysis Methodology - NAM [34][33][17]: models the social rules identified and specified as the conditions and constraints for realizations of the affordances, considering typical behavior of research scenario gathered by surveys [22].

\subsection{SAM and Social Affordances}

We subscribe to the notion that the world is socially and subjectively constructed [30]. Considering this, Stamper proposed that Gibson's theory of affordance can be naturally extended to the social world for studying social behavior, and introduced the concept of social affordance, which has been applied in the OS domain as "a pattern of behavior that is shared in a social community", has a start and finish time, and a starting and finishing authority [10][17].

In this sense, before promoting a change in the way people relate to energy, it is important to understand current patterns of behavior, which are, according to literature, mostly unconscious and guided by the environment [14][25]; and according to data gathered in local surveys, they are not directly related to the natural environment people live in [22]. This way, it could be possible to establish target norms, or behaviors that the new technology intends to promote.

The ontology model, part of the SAM, maps the vocabulary of the problem domain and graphically represents the nature of reality by ontological (and temporal) dependencies between affordances and agents [30][10]. Agents (graphically represented by ellipses) are affordances that can take responsibility for their actions and actions of others [27]. Both agents and affordances can have attributes called determiners. Figure 1 illustrates the ontology model of this study considering firstly the current state (in gray), then the possible future reality by means of a new technology (in white).

In the current reality, a particular Society is the root agent of the model, which means it affords, i.e. determines how we conceptualize and perceive the "natural environment" and the natural resources that the agent Energy generator uses in the generation process, such as water from dams. This energy is then distributed to existing buildings by the Energy distributor, which means that the energy distribution ontologically depends on the natural resources and energy produced by the Energy generator agent. The affordance energy consumption, which is represented in $\mathrm{kWh}$, depends on the distribution and on the agent person (who consumes it) to exist. The Energy metering affordance depends on the consumption and distribution to measure and to show the consumption through its display. Reading this display to generate the 
bill is an Energy distributor responsibility, while the bill payment is a householder's responsibility. The energy consumption impacts the natural environment via energy generation. However, the person who consumes energy in households, schools, etc., is not aware of this connection.

In the new scenario, represented in white, a public display (the SEETree) appears as an affordance of buildings. It consists on a public installation located in a building that is attended by groups of people. By means of the public display, people may establish an agreement and configure collective saving actions by setting the level of consumption reduction, the number of days to achieve this challenge, and identifying those buildings with smart metering that will join the challenge. The collective action is intended to create an awareness of the impact of the energy consumption in the natural environment, possibly motivating people to more conscious energy consumption; the target people are both: who are part of groups, and those motivated by them.

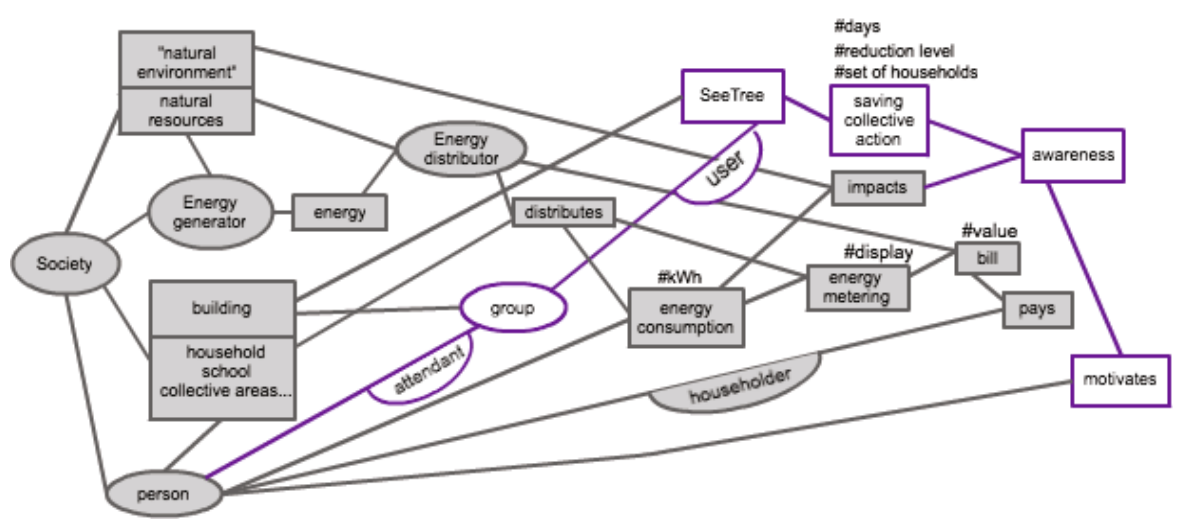

Fig. 1. The Ontology Chart of the relation with energy and the Social EFT proposal

The ontology chart (OC) in Fig. 1 differs in some epistemological aspects from a conventional OC [10][17] or "Stamper's OC"[34]. We thus call the type of OC presented in Fig. 1 OC for Intended Reality (OC4IR). Table 1 lists the main differences between the two types. In short, an OC4IR extends an OC with a part that models a possible future reality that is intended by the designers and possibly other existing or new stakeholders. Since it might introduce new affordances, agents, and ontological dependencies, it is conceivable that there are additional stakeholders in this future reality. The OC4IR is an intermediary document: once the innovation is being designed and disseminated, the OC4IR serves as the blueprint for the next OC that then represents the "new" actual reality. Consequently, it can be expected that the "new" OC deviates in some aspects from the OC4IR, as new stakeholders create a shared understanding of the new reality. For instance, if, for different reasons, awareness of the impact of energy consumption is still not afforded as expected, this will be reflected in the new OC. Furthermore, even parts of the "old" OC might 
change, e.g., if new stakeholders with new insights are introduced that result in a different shared understanding. The most notable difference between an OC and an OC4IR lies in the "affordances" of the intended future reality.

Table 1. Comparing Stamper's OC with the OC for Intended Reality

\begin{tabular}{|c|c|c|}
\hline & Stamper's OC & OC4IR \\
\hline $\begin{array}{l}\text { What is } \\
\text { modeled? }\end{array}$ & $\begin{array}{l}\text { An ontology in the philosophical } \\
\text { sense, i.e. a shared representation } \\
\text { of actual reality. }\end{array}$ & $\begin{array}{l}\text { Apart from actual reality, a possible } \\
\text { future reality as intended by } \\
\text { designers. }\end{array}$ \\
\hline $\begin{array}{l}\text { Who } \\
\text { subscribes to } \\
\text { the model? }\end{array}$ & All involved stakeholders. & $\begin{array}{l}\text { All stakeholders subscribe to the part } \\
\text { that models actual reality, at least } \\
\text { designers subscribe to the possible } \\
\text { future reality. }\end{array}$ \\
\hline $\begin{array}{l}\text { Purpose of } \\
\text { the model? }\end{array}$ & $\begin{array}{l}\text { To document a shared model of } \\
\text { actual reality (the Information } \\
\text { System) and to eventually create a } \\
\text { computational representation of } \\
\text { the technical Information System. }\end{array}$ & $\begin{array}{l}\text { Document the designers' (and } \\
\text { possibly other stakeholders') } \\
\text { understanding of the innovation task. } \\
\text { Inform design: define new } \\
\text { stakeholders, affordances, norms, } \\
\text { and assumptions about the future, } \\
\text { leading to requirements. }\end{array}$ \\
\hline Agent & As defined in $[10,30]$. & $\begin{array}{l}\text { As defined in }[10,30] \text {; new agents } \\
\text { become stakeholders. }\end{array}$ \\
\hline Affordance & As defined in $[10,30]$. & $\begin{array}{l}\text { Affordances of actual reality }\left(\mathrm{A}_{\mathrm{act}}\right) \text { as } \\
\text { defined in }[10,30] \text {; "affordances" of } \\
\text { possible reality }\left(\mathrm{A}_{\text {pos }}\right) \text { still need to be } \\
\text { established and made perceivable } \rightarrow \\
\text { core challenge of design intention. }\end{array}$ \\
\hline $\begin{array}{l}\text { Ontological } \\
\text { dependency }\end{array}$ & As defined in $[10,30]$. & As defined in $[10,30]$. \\
\hline Norm & $\begin{array}{l}\text { As defined in }[10,30] \text {; prevalence } \\
\text { of behavioral norms, expressed in } \\
\text { deontic logic. }\end{array}$ & $\begin{array}{l}\text { Additionally: other types/categories } \\
\text { of norms regarding intentions, } \\
\text { expectations or motivations. }\end{array}$ \\
\hline
\end{tabular}

\section{Norms}

An organization can be seen as a system of social norms, which have the function of determining patterns of behavior, and whether they are legal or acceptable within the social context, defining a culture. Norms are developed as collective affordances through practical experiences of people (agents) in the society, influencing how people perceive the world, make judgments and possibly guiding their behavior according to a subjective evaluation of a situation. Norms can be manipulated, applied and disregarded accordingly [35].

Behavioral norms, for example, are described according to the structure of an explicit rule 
for a certain community and a certain purpose,

if $\underline{x}$ then $\underline{A}$ is (obliged/permitted/forbidden) to do $\underline{y}$

where $\underline{x}$ is some perception of the situation, $\underline{A}$ is a responsible agent (a person or group of people) and $\underline{y}$ is the action. The agent $\underline{A}$ can only act in accordance with the norms of the community for the given purpose if he/she/it has the information necessary for perceiving the situation and the power to communicate other information where the action calls for it [31].

Table 2 summarizes norms classification found in OS literature [17][34]:

Table 2. Types of norms [17][34]

\begin{tabular}{|c|c|c|}
\hline Criteria & $\begin{array}{l}\text { Types of } \\
\text { norms }\end{array}$ & Description \\
\hline \multirow{3}{*}{ Formality } & Informal & $\begin{array}{l}\text { Norms that are known by people who can live according to } \\
\text { them without their being able to express them in writing. }\end{array}$ \\
\hline & Formal & $\begin{array}{l}\text { Norms that can be performed by people following explicit } \\
\text { written norms or rules which they can be trained to perform } \\
\text { in a rather mechanical way. }\end{array}$ \\
\hline & Technical & $\begin{array}{l}\text { Norms that are handled in this way or are so exactly } \\
\text { specified as to be capable of automation. }\end{array}$ \\
\hline \multirow{5}{*}{$\begin{array}{l}\text { Aspects } \\
\text { of the } \\
\text { behavior } \\
\text { they } \\
\text { govern }\end{array}$} & Perceptual & $\begin{array}{l}\text { How people receive signals from the environment via their } \\
\text { senses through media such as light, sound and taste. }\end{array}$ \\
\hline & Cognitive & $\begin{array}{l}\text { Enable one to incorporate the beliefs and knowledge of a } \\
\text { culture, to interpret what is perceived, and to gain an } \\
\text { understanding based on existing knowledge. }\end{array}$ \\
\hline & Evaluative & $\begin{array}{l}\text { Help explain why people have certain beliefs, values, and } \\
\text { objectives. Vary between cultures. }\end{array}$ \\
\hline & Behavioral & Govern people within regular pattern. \\
\hline & Denotative & $\begin{array}{l}\text { Direct the choices of signs for signifying; such choices are } \\
\text { culture-dependent, such as certain colors to signify } \\
\text { happiness. }\end{array}$ \\
\hline \multirow{4}{*}{$\begin{array}{l}\text { The effects } \\
\text { of their } \\
\text { execution }\end{array}$} & $\begin{array}{l}\text { Standing } \\
\text { orders }\end{array}$ & $\begin{array}{l}\text { Result in a change in the physical world, because they are } \\
\text { commands to perform actions, expressed as one may, may } \\
\text { not, must or must not do something. }\end{array}$ \\
\hline & Status & $\begin{array}{l}\text { Define social structure and legal relations, designating } \\
\text { liability, right or no-right over certain events or actions. }\end{array}$ \\
\hline & $\begin{array}{l}\text { Powers of } \\
\text { intervention }\end{array}$ & Invoke or inhibit the use of existing standing orders. \\
\hline & $\begin{array}{l}\text { Legislative } \\
\text { powers }\end{array}$ & Change other norms. \\
\hline \multirow{3}{*}{$\begin{array}{l}\text { Types of } \\
\text { objects } \\
\text { that they } \\
\text { are applied } \\
\text { to }\end{array}$} & Substantive & Core business function and operation. \\
\hline & $\begin{array}{l}\text { Communi- } \\
\text { cation }\end{array}$ & $\begin{array}{l}\text { Patterns, structures and procedures of communication } \\
\text { within an organization. }\end{array}$ \\
\hline & Control & $\begin{array}{l}\text { Introduce sanctions and rewards, acting as a mechanism to } \\
\text { reinforce that everyone does what he or she is supposed to } \\
\text { do, as prescribed by other two types of norms. }\end{array}$ \\
\hline
\end{tabular}


According to the Semantic Analysis and the OC4IR, in the next session norms from the actual reality and intended reality are described.

\subsection{Identified Norms and Behavior}

In preliminary work [21], a set of norms was identified based on interviews with energy company employees, most of them regarding commercial relationship between customers and the energy company, i.e., how people prioritize energy bill payment among other monthly bills, or reasons to adopt an illegal connection instead of paying for the energy regularly. Part of this set of norms is considered here because they express values and, consequently, how people relate to energy.

Beyond this qualitative analysis, two surveys done as part of Smart Grid deployment projects also subsidize norms identification. A total of 280 householders members of the projects answered a questionnaire of about 140 questions in the Brazilian state of Minas Gerais, which is partially urban and mostly rural; other 165 householders participated of the survey in the city of Rio de Janeiro, most of them from low-income areas. Interviews were conducted face-to-face by a research institute in 2011 in Minas Gerais and in 2012 in Rio de Janeiro. Results of the survey previously analyzed [22] and related to social life, environmental concerns, motivation, and how they relate to energy and to each other in daily life were selected to set norms.

Table 3 describes the norms and presents their classification from the Table 1, firstly in terms of formality informal, formal and technical levels, then according to the other types of norms. Entities represented in the first part are related to the traditional OC (actual reality), followed by those related to the OC4IR.

\subsection{Discussion}

From the collection of norms, we observe that the actual scenario is mostly constituted by formal and technical norms, while the possible future reality is dominated by informal norms, especially those related to the social psychological view. This is aligned to the intended aim of the new technology design of promoting behavior change. As for the aspects of behavior they govern, we notice more evaluative norms in the new set, suggesting more involvement of people in the joint action and collective achievement. Regarding the types of objects that the new set of norms are applied to, there is predominance of communication over control or substantive norms, as the whole scenario inherits the substantive norms of the OC. The norms description also indicates some elements to drive the design (underlined), such as green area, flooding, natural environment, trash disposal, etc. 
Table 3. Norms description according to the actual reality and intended reality

\begin{tabular}{|c|c|c|c|}
\hline Entity & Norm description & $\mathbf{I} / \mathbf{F} / \mathbf{T}$ & $\begin{array}{c}\text { Type of } \\
\text { norm }\end{array}$ \\
\hline \multicolumn{4}{|c|}{ Actual reality norms (OC) } \\
\hline \multirow{3}{*}{ 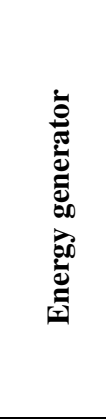 } & $\begin{array}{l}\text { ALWAYS when the energy consumption increases, THEN } \\
\text { energy generator MUST produce more energy to supply the } \\
\text { demand }\end{array}$ & $\mathrm{T}$ & $\begin{array}{l}\text { Standing } \\
\text { order, } \\
\text { Substantive }\end{array}$ \\
\hline & $\begin{array}{l}\text { ALWAYS when the energy consumption is predicted to } \\
\text { reach the limit, THEN the government HAVE TO plan new } \\
\text { power plants construction to generate more energy }\end{array}$ & $\begin{array}{l}\mathrm{T} \\
\mathrm{F}\end{array}$ & $\begin{array}{c}\text { Power of } \\
\text { intervention }\end{array}$ \\
\hline & $\begin{array}{l}\text { SOMETIMES, when the demand for energy is close to reach } \\
\text { the limit, THEN the Energy generator MUST activate } \\
\text { thermoelectric power plants }\end{array}$ & $\mathrm{F}$ & $\begin{array}{l}\text { Standing } \\
\text { order. } \\
\text { Power of } \\
\text { intervention }\end{array}$ \\
\hline \multirow{2}{*}{ 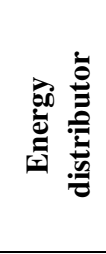 } & $\begin{array}{l}\text { ALWAYS when a person wants to have energy in a building, } \\
\text { THEN the Energy distributor MUST install an energy } \\
\text { metering }\end{array}$ & $\begin{array}{l}\mathrm{T} \\
\mathrm{F}\end{array}$ & Status \\
\hline & $\begin{array}{l}\text { WHENEVER when the month is about to end, THEN the } \\
\text { Energy distributor HAVE TO read the consumption } \\
\text { registered by the meter }\end{array}$ & $\mathrm{F}$ & Substantive \\
\hline 总 & $\begin{array}{l}\text { MOST OF TIMES, when new power plants must be built, } \\
\text { THEN new green areas HAVE TO be flooded to create new } \\
\text { dams }\end{array}$ & $\mathrm{T}$ & Status \\
\hline \multirow{2}{*}{ 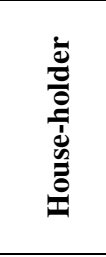 } & $\begin{array}{l}\text { MONTHLY, when the Energy distributor sends the bill, } \\
\text { THEN the householder HAVE TO pay for the energy } \\
\text { consumed }\end{array}$ & $\mathrm{F}$ & Status \\
\hline & $\begin{array}{l}\text { MOST OF TIMES, when the householder pays the bill, } \\
\text { THEN he/she SHOULD be aware of the amount of energy } \\
\text { they have consumed (they are not [21]) }\end{array}$ & I & Cognitive \\
\hline \multirow{3}{*}{ 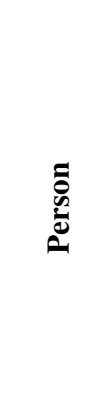 } & $\begin{array}{l}\text { MOST OF TIMES, when in contact with people who do not } \\
\text { pay for energy THEN consumers MAY believe that they } \\
\text { should not pay for energy too [21] }\end{array}$ & I & Denotative \\
\hline & $\begin{array}{l}\text { MOST OF TIMES, when having incomplete education level } \\
\text { THEN a person may not make sense of concepts associated } \\
\text { with the energy consumption and its bill (kWh), \%, charts } \\
\text { [21] }\end{array}$ & I & Cognitive \\
\hline & $\begin{array}{l}\text { FREQUENTLY, when having a household budget increase } \\
\text { THEN low-privileged consumers CAN buy more new } \\
\text { domestic electronic devices [21] }\end{array}$ & $\mathrm{F}$ & Evaluative \\
\hline
\end{tabular}




\begin{tabular}{|c|c|c|c|}
\hline \multicolumn{4}{|c|}{ Intended reality norms (OC4IR) } \\
\hline \multirow{2}{*}{ 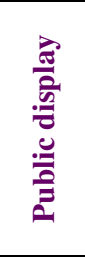 } & $\begin{array}{l}\text { ALWAYS, when motivated to consume energy consciously } \\
\text { THEN users MUST receive objective information from the } \\
\text { public display about individual consumption that helps them } \\
\text { to act accordingly }\end{array}$ & $\mathrm{F}$ & $\begin{array}{l}\text { Behavioral, } \\
\text { Communi- } \\
\text { cation }\end{array}$ \\
\hline & $\begin{array}{l}\text { ALWAYS, when participating of a saving collective action } \\
\text { THEN groups MUST see partial results of the action in a } \\
\text { motivating way considering participants household measures }\end{array}$ & $\mathrm{T}$ & $\begin{array}{l}\text { Control, } \\
\text { Percepual }\end{array}$ \\
\hline \multirow{3}{*}{ 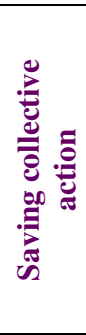 } & $\begin{array}{l}\text { ALWAYS when involved with a collective saving energy } \\
\text { challenge THEN users MUST understand the importance of } \\
\text { individual contribution to collective achievements }\end{array}$ & I & Cognitive \\
\hline & $\begin{array}{l}\text { ALWAYS when establishing a collective action THEN users } \\
\text { MUST discuss and agree about each user and his/her family } \\
\text { commitment }\end{array}$ & I & $\begin{array}{c}\text { Evaluative, } \\
\text { Standing } \\
\text { order }\end{array}$ \\
\hline & $\begin{array}{l}\text { ALWAYS when establishing a collective challenge THEN } \\
\text { group MUST determine a period to achieve it }\end{array}$ & $\mathrm{T}$ & $\begin{array}{c}\text { Behavioral, } \\
\text { Standing } \\
\text { order }\end{array}$ \\
\hline \multirow{5}{*}{ 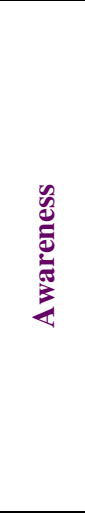 } & $\begin{array}{l}\text { MOST OF TIMES when using electricity in the household } \\
\text { THEN users MAY think about natural resources } \\
\text { consumptions }\end{array}$ & I & $\begin{array}{l}\text { Evaluative } \\
\text { Cognitive }\end{array}$ \\
\hline & $\begin{array}{l}\text { FREQUENTLY when using electricity in the households } \\
\text { THEN users SHOULD discuss about energy consumption } \\
\text { and the natural environment }\end{array}$ & I & $\begin{array}{l}\text { Cognitive, } \\
\text { Communica } \\
\text { tion }\end{array}$ \\
\hline & $\begin{array}{l}\text { MOST OF TIMES when interested in preserving the natural } \\
\text { environment THEN person SHOULD consider other natural } \\
\text { resources, not restricting it to recycling/trash disposal [21] }\end{array}$ & I & Denotative \\
\hline & $\begin{array}{l}\text { MOST OF TIMES when wasting energy THEN individuals } \\
\text { SHOULD relate it to environmental consequences }\end{array}$ & I & $\begin{array}{l}\text { Evaluative } \\
\text { Perceptual } \\
\end{array}$ \\
\hline & $\begin{array}{l}\text { FREQUENTLY when interested in consciously consuming } \\
\text { energy THEN families SHOULD check and discuss about } \\
\text { the current consumption [21] }\end{array}$ & $\mathrm{I}$ & $\begin{array}{l}\text { Behavioral } \\
\text { Communi- } \\
\text { cation }\end{array}$ \\
\hline \multirow{3}{*}{ 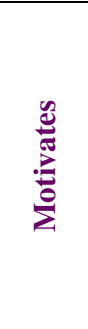 } & $\begin{array}{l}\text { ALWAYS when involved with a collective saving collective } \\
\text { action THEN users MAY motivate other people in the } \\
\text { society to consume more consciously [21] }\end{array}$ & I & Evaluative \\
\hline & $\begin{array}{l}\text { ALWAYS when involved with a collective saving energy } \\
\text { challenge THEN users SHOULD engage their family in the } \\
\text { commitment [21] }\end{array}$ & I & Behavioral \\
\hline & $\begin{array}{l}\text { FREQUENTLY when involved with a saving commitment } \\
\text { THEN users MAY want to share their achievements with } \\
\text { people they know [21] }\end{array}$ & $\mathrm{I}$ & $\begin{array}{l}\text { Evaluative, } \\
\text { Communi- } \\
\text { cation }\end{array}$ \\
\hline
\end{tabular}

\section{Conclusion}

The relation between energy consumption and its environmental impact is weak or even almost inexistent in some sociocultural scenarios. This paper presented the concept of Social Eco-feedback Technology, drawing on the social affordance notion and on the analysis of data regarding the connection of energy consumption and the natural environment in Brazil. This approach to energy feedback differs from those in 
the state of the art firstly by dealing with low-income areas in a developing scenario, and then by proposing a collective interactive solution for a public area.

The analysis and design process have been based on Organizational Semiotics artifacts, which helps to analyze information systems and the introduction of a technology within a social dimension. To consider the possible future influences by this technology, an adaptation of traditional artifacts of Organizational Semiotics was made. Further work involves designing a system that enables the informal and formal norms regarding collective saving interaction and then evaluating the technical solution proposal with regard to its potential for promoting the intended social behavior change.

\section{References}

1. Accenture. Understanding Consumer Preferences in Energy Efficiency, http: / /www.accenture.com/us-en/Pages /

insight-understanding-consumer-preferences-energyefficiency-utilities-summary.aspx

2. Banco Mundial. Consumo de Energia Eléctrica (kWh Per Capita), http: / / datos. bancomundial .org/indicador/EG. USE. ELEC.KH. PC .

3. Brazil. Ten Year Plan for Energy Expansion (PDE 2017), http: / /www. epe.gov.br/PDEE/Forms / EPEEstudo.aspx

4. Darby, S.: Smart metering: what potential for householder engagement? Building Research and Information 38(5), 442-457 (2010)

5. Dick, H., Eden, H., Fischer, G.: From consumers to owners: Using meta-design environments to motivate changes in energy consumption. In: Piccinno, A. (ed.) IS-EUD 2011. LNCS, vol. 6654, pp. 319-324. Springer, Heidelberg (2011)

6. Dourish, P.: HCI and environmental sustainability: the politics of design and the design of politics. In: Proceedings of the DIS 2010, pp. 1-10. ACM (2010)

7. European Commission. Energy Sources, Production Costs and Performance of Technologies for Power Generation, Heating and Transport, COM(2008)744. Brussels, Belgium (2008)

8. Froehlich, J., et al.: The design and evaluation of prototype eco-feedback displays for fixture-level water usage data. In: Proceedings of CHI 2012, pp. 2367-2376 (2012)

9. Froehlich, J., Findlater, L., Landay, J.: The design of eco-feedback technology. In: Proceedings of CHI 2010, pp. 1999-2008. ACM (2010)

10. Gazendam, M., Liu, K.: The evolution of organisational semiotics: A brief review of the contribution of Ronald Stamper. Studies in Organisational Semiotics. Kluwer Academic Publishers, Dordrecht (2005)

11. Gibson, J.J.: The Ecological Approach to Visual Perception. Houghton Mifflin, Boston (1979)

12. Goldstein, J.N., Cialdini, R.B., Griskevicius, V.: A Room with a Viewpoint: Using Social Norms to Motivate Environ. Conservation in Hotels. J. of Consumer Research (October 2008)

13. Hall, E.T.: The Silent Language. Anchor Books (1959)

14. Jelsma, J.: Designing 'Moralized' products: theory and practice. In: Verbeek, P.-P., Slob, A. (eds.) User Behaviour and Technology Development, pp. 221-231. Springer (2006)

15. Johnson, P.H., et al.: Beyond kWh: Myths and fixes for energy competition game design. In: Proc. of the Meaningful Play Conference (2012) 
16. Kolkman, M.: Problem Articulation Methodology: PhD thesis, University of Twente, Enschede (1993) ISBN 90-9005972-5

17. Liu, K.: Semiotics in Information Systems Engineering. Cambridge University Press, Cambridge (2000)

18. Norman, D.: Affordance, conventions, and design. Interactions 6(3), 38-43 (1999)

19. Norman, D.: Simplicity is not the answer. Interactions 15(5), 45-46 (2008)

20. Norman, D.: The Design of Everyday Things. Doubleday, New York (1988)

21. Piccolo, L.S.G., Baranauskas, M.C.C.: Motivational Aspects in Energy Feedback Systems Design. In: Proc. of IHC+CLIHC, pp. 313-328. ACM (2010)

22. Piccolo, L.S.G., Baranauskas, M.C.C.: Climbing the Ladder with Energy: informing the design of Eco-Feedback Technology with a Social Approach. In: Proc. of the 14th Intl. Conf. on Informatics and Semiotics in Organisations (ICISO 2013). Springer (to be published 2013)

23. Pierce, J., et al.: Some consideration on the (in)effectiveness of residential energy feedback systems. In: Proceedings of the DIS 2010, pp. 244-247. ACM (2010)

24. Pierce, J., Paulos, E.: Beyond energy monitors: interaction, energy, and emerging energy systems. In: Proceedings of CHI 2012, pp. 665-674. ACM (2012)

25. Pierce, J., Schiano, D.J., Paulos, E.: Home, habits, and energy: examining domestic interactions and energy consumption. In: Proc. of CHI 2010, pp. 1985-1994. ACM (2010)

26. Rokeach, M.: Long-term Value Change Initiated by Computer Feedback. In: Rokeach, M. (ed.) Understanding Human Values: Individual and Societal, pp. 210-225. The Free Press (1979)

27. Salter, A., Liu, K.: Using Semantic Analysis and Norm Analysis to Model Organisations. In: Proceedings of ICEIS (2002)

28. Sanders, K.R., Atwood, L.E.: Value Change Initiated by the Mass Media. In: Rokeach, M. (ed.) Understanding Human Values: Individual and Societal, pp. 226-240. The Free Press (1979)

29. Spagnolli, A., et al.: Eco-Feedback on the Go: Motivating Energy Awareness. Computer 44(5), 38-45 (2011)

30. Stamper, R.K.: Organisational semiotics: Informatics without the computer? In: Information, Organisation and Technology: Studies in Organisational Semiotics, pp. 115171. Kluwer Academic Publishers, Boston (2001)

31. Stamper, R.K.: Social Norms in Requirements Analysis - an outline of MEASUR. In: Requirements Engineering, Technical and Social Aspects. Academic Press, N.Y (1994)

32. Stamper, R.K., Althaus, K., Backhouse, J.: MEASUR: Method for Eliciting, Analyzing and Specifying User Requirements. In: Computerized Assistance During the Information Systems Life Cycle. Elsevier Science Publishers, North-Holland (1988)

33. Stamper, R., et al.: Semiotic Methods for Enterprise Design and IT Applications. In: Proc. of the 7th Int. Workshop on Organisational Semiotics, pp. 190-213 (2004)

34. Stamper, R., Liu, K., et al.: Understanding the Roles of Signs and Norms in Organisations: a semiotic approach to information system design. Journal of Behaviour \& Information Technology 19(1), 15-27 (2000)

35. Stamper, R.K.: Social Norms in Requirements Analysis - an outline of MEASUR. In: Jirotka, M., Goguen, J., Bickerton, M. (eds.) Requirements Engineering Technical and Social Aspects. Academic Press, New York (1993)

36. US Department of Energy. The Smart Grid: An introduction, http: / / www.oe.energy.gov/DocumentsandMedia/ DOE_SG_Book_Single_Pages.pdf

37. WWF International. Living Planet Report WWF, Gland, Switzerland (2012) 